\title{
Doxorubicin Cardiomyopathy
}

\author{
Kanu Chatterjee $^{a}$ Jianqing Zhang ${ }^{b}$ Norman Honbo ${ }^{b}$ Joel S. Karliner ${ }^{b, c}$ \\ a Department of Medicine, University of lowa Carver College of Medicine, lowa City, lowa, \\ ${ }^{b}$ Cardiology Section (111C5), VA Medical Center, and ${ }^{~ C}$ Cardiovascular Research Institute, University of California, \\ San Francisco, Calif., USA
}

\section{Key Words}

Adriamycin · Anthracyclines · Cardiomyocytes •

Cardiomyopathy $\cdot$ Doxorubicin $\cdot$ Vincristine

\begin{abstract}
Established doxorubicin cardiomyopathy is a lethal disease. When congestive heart failure develops, mortality is approximately $50 \%$. Extensive research has been done to understand the mechanism and pathophysiology of doxorubicin cardiomyopathy, and considerable knowledge and experience has been gained. Unfortunately, no effective treatment for established doxorubicin cardiomyopathy is presently available. Extensive research has been done and is being done to discover preventive treatments. However an effective and clinically applicable preventive treatment is yet to be discovered.

Copyright $\odot 2009$ S. Karger AG, Basel
\end{abstract}

\section{Introduction}

The anthracycline anticancer drug doxorubicin is an effective and frequently used chemotherapeutic agent for various malignancies $[1,2]$. Its major adverse effect is cardiotoxicity, which may limit its use. Doxorubicin cardiomyopathy, once developed, carries a poor prognosis and is frequently fatal $[2,3]$. The presently available treatment of established cardiomyopathy does not appear to improve prognosis. Thus, many preventive treatments have been proposed. This review briefly discusses the pathophysiology and management strategies of doxorubicin cardiomyopathy including the experimental drugs that have been tested to prevent its cardiotoxicity.

\section{Cardiotoxicity: Incidence}

Doxorubicin cardiotoxicity can be acute, occurring during and within 2-3 days of its administration. The incidence of acute cardiotoxicity is approximately $11 \%$ [3, 4]. The manifestations are usually chest pain due to myopericarditis and/or palpitations due to sinus tachycardia, paroxysmal nonsustained supraventricular tachycardia and premature atrial and ventricular beats. The electrocardiogram may reveal nonspecific ST-T changes, left axis deviation and decreased amplitude of QRS complexes. The mechanisms for these acute changes are not clear but may be due to doxorubicin-induced myocardial edema, which is reversible $[3,5]$. Acute left-ventricular (LV) failure is a rare manifestation of acute cardiotoxicity, but it is also reversible with appropriate treatments.

Parts of this study were presented at the Annual Meetings of the European Society of Cardiology in 2007 and 2008.

\section{KARGER}

Fax +41613061234

E-Mail karger@karger.ch

www.karger.com (c) 2009 S. Karger AG, Basel

$0008-6312 / 10 / 1152-0155 \$ 26.00 / 0$

Accessible online at:

www.karger.com/crd
Kanu Chatterjee

Division of Cardiology, Department of Medicine

University of Iowa Carver College of Medicine, Room/Bldg E-314-4 GH

200 Hawkins Drive, Iowa City, IA 52242-1081 (USA)

Tel. +1 319353 7789, Fax +1 319353 6343, E-Mail kanu-chatterjee@ uiowa.edu 
Fig. 1. a Normal myocyte structure and without abnormal interstitial fibrosis. b Myofibrillar loss and vacuolization (Adria cells) and extensive diffuse fibrosis. (Published with permission from Takemura et al. [3])
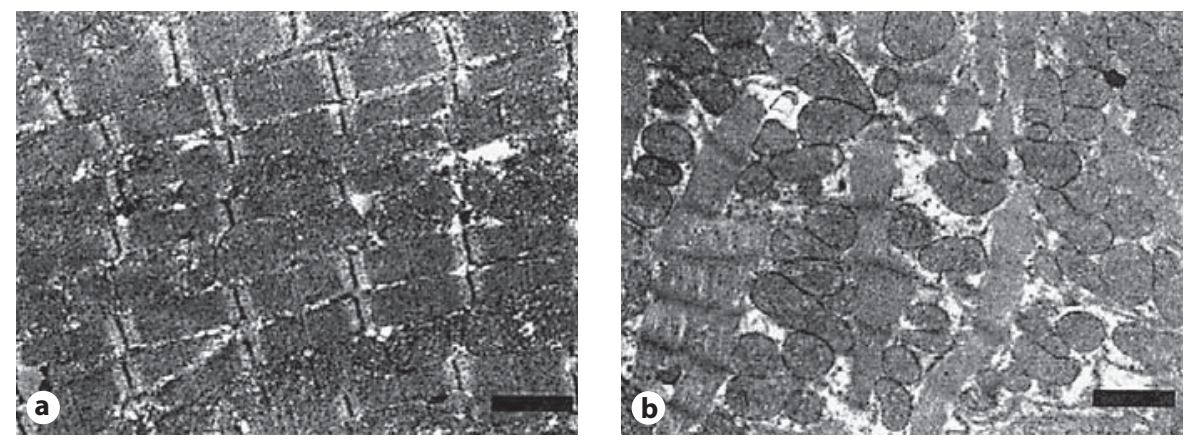

The incidence of chronic doxorubicin cardiotoxicity is much lower, with an estimated incidence of about $1.7 \%$ [6]. It is usually evident within 30 days of administration of its last dose, but it may occur even after 6-10 years after its administration. The incidence of doxorubicin cardiomyopathy is primarily related to its dose. The incidence is about $4 \%$ when the dose of doxorubicin is 500 $550 \mathrm{mg} / \mathrm{m}^{2}, 18 \%$ when the dose is $551-600 \mathrm{mg} / \mathrm{m}^{2}$ and $36 \%$ when the dose exceeds $600 \mathrm{mg} / \mathrm{m}^{2}$ [7]. The other risk factors are combination therapy with other cardiotoxic antitumor drugs and mediastinal radiation therapy. Cancer therapy in childhood and adolescence predisposes to the development of doxorubicin cardiomyopathy in adults [8]. Age also influences the risk of developing doxorubicin cardiomyopathy. Very young and very old individuals are more prone to develop this complication. A history of cardiovascular disease such as hypertension and reduced LV ejection fraction before therapy is also a risk factor to develop this complication. The prognosis of patients who develop congestive heart failure is poor $(\sim 50 \%$ mortality in 1 year) [6].

\section{Cardiac Morphologic and Functional Changes}

The cardiac morphologic and functional derangements of doxorubicin cardiomyopathy are similar to those of dilated cardiomyopathy. All four cardiac chambers may be dilated although severe dilatations of ventricles and atria are less common than in ischemic and non-ischemic dilated cardiomyopathies. The ventricular ejection fraction and contractile function is reduced. There is concomitant diastolic dysfunction. Because of insignificant change in LV wall thickness, wall stress is increased. Mural thrombi are also detected in some patients.

\section{Histopathologic Changes}

In doxorubicin cardiomyopathy, there are areas of patchy myocardial interstitial fibrosis and scattered vacuolated cardiomyocytes (Adria cells; fig. 1). Adria cells are seen adjacent to areas of fibrosis. The areas of fibrosis are usually widespread and areas of acute myocyte damage are infrequent. There is fibroblast proliferation and histiocyte infiltration in the areas of healed myocarditis. Partial or total loss of myofibrils and myocyte vacuolar degeneration are essential features of doxorubicin cardiotoxicity (fig. 2). With loss of myofilaments, the remnants of $Z$ discs are seen. There is distention of sarcoplasmic reticulum and the T-tubules. The myocyte vacuoles coalesce and form large membrane-bound spaces. The nucleus-chromatin disorganization and replacement of chromatin by pale filaments are also features of doxorubicin cardiomyopathy $[3,9,10]$.

\section{Mechanism of Doxorubicin Cardiomyopathy}

The mechanisms of therapeutic effects of doxorubicin on tumor cells are different from those of the mechanisms of its cardiotoxicity. The proposed mechanisms of its anti-malignancy effects include intercalation into DNA leading to inhibition of synthesis of macromolecules, generation of reactive oxygen species, DNA binding and DNA cross-linking; DNA damage by inhibition of topoisomerase II, and induction of apoptosis by inhibition of topoisomerase II $[3,11,12]$.

The proposed principal mechanisms of doxorubicin cardiotoxicity are increased oxidative stress, as evident from increased levels of reactive oxygen species and lipid peroxidation $[3,5,13,14]$. Decreased levels of antioxidants and sulfhydryl groups $[5,15-18]$, inhibition of nucleic acid and protein synthesis $[19,20]$, release of vasoac- 

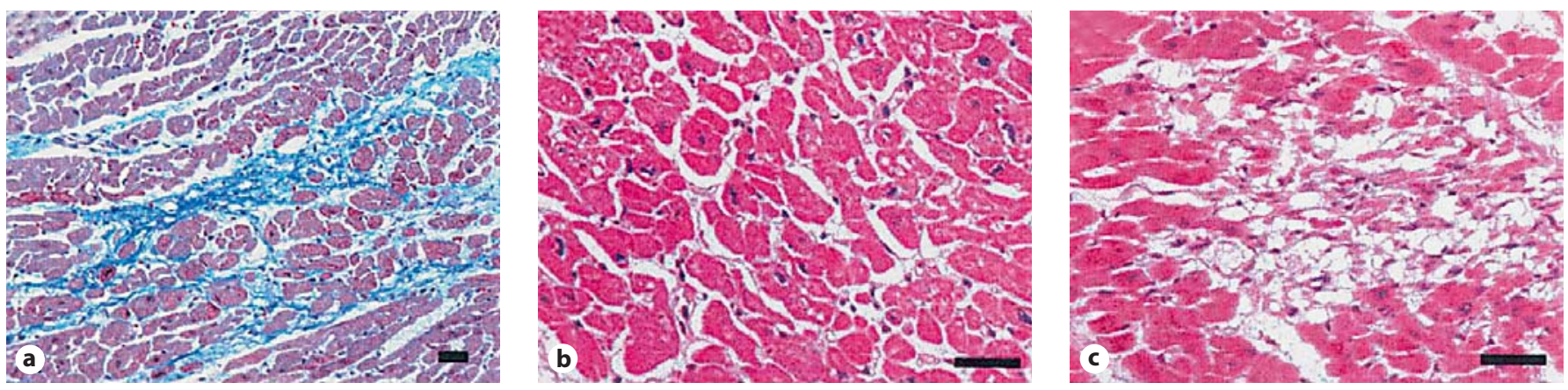

Fig. 2. a Normal myocardium with little or no extracellular matrix changes and intact myocytes. b Same features in higher magnification. c Myocyte loss, matrix disorganization and diffuse fibrosis. (Published with permission from Takemura et al. [3])

tive amines [21], altered adrenergic function [22] and decreased expression of cardiac-specific genes are other proposed mechanisms [3]. It is possible that more than one mechanism is operative. It should also be emphasized that the importance of many of the proposed mechanisms remains to be established.

\section{Oxidative Stress}

Doxorubicin appears to induce toxic damage to the mitochondria of cardiomyocytes. Several mitochondrial enzymes such as NADH dehydrogenase, cytochrome P450 reductase and xanthine oxidase are involved in generating oxygen free radicals (reactive oxygen species) [3, 23-25]. Doxorubicin also increases superoxide formation by increasing endothelial nitric oxide synthase [26, 27], which promotes intracellular hydrogen peroxide formation [28].

\section{Gene Expression}

The downregulation of $\alpha$-actin, myosin light and heavy chains, troponin-I, and desmin proteins by doxorubicin has been suggested as a potential mechanism of its cardiotoxicity. Decreased expression of the contractile proteins is associated with myofibrillar loss and reduced myocardial contractile function [29, 30]. Downregulation of sarcoplasmic reticular ATPase may cause abnormal myocardial diastolic function $[3,29,30]$. It has been suggested that doxorubicin can inactivate extracellular signal-regulated kinase (ERK) [31].

\section{Apoptosis}

There is evidence that doxorubicin induces apoptosis of cardiomyocytes [28, 32, 33]. Formation of hydrogen peroxide and superoxide has been implicated in doxoru- bicin-induced cardiomyocyte toxicity $[28,32]$. These intracellular oxidants induce p53, and activated p53 promotes apoptosis of cardiomyocytes [35, 36].

\section{Diagnosis}

The diagnosis of doxorubicin cardiomyopathy should consist of taking appropriate history to assess the likelihood of the diagnosis. A complete examination of the cardiovascular system to detect presence of signs of overt heart failure, such as elevated jugular venous pressure and S3 gallop, is essential. An electrocardiogram should be obtained, which usually demonstrates nonspecific ST-T wave changes and sometimes low-voltage QRS complexes. A chest X-ray is also helpful to assess cardiomegaly and signs of pulmonary venous congestion. It should be emphasized that the presence or absence of the abnormalities by these evaluations are nonspecific and nondiagnostic.

Echocardiography with Doppler studies is commonly used to detect early diastolic and systolic LV dysfunction. Exercise echocardiography may also be useful to assess LV contractile reserve.

Radionuclide ventriculography has been used to assess LV systolic and diastolic function. Like other types of cardiomyopathy, cardiac adrenergic denervation occurs in doxorubicin cardiomyopathy. MIBG (metaiodobenzylguanidine) nuclear imaging can be employed to assess cardiac adrenergic denervation [37]. Impaired glucose and fatty acid metabolism has been observed in doxorubicin cardiomyopathy. Impaired myocardial glucose uptake can be assessed by positron emission tomography using fluorine $-{ }^{18} \mathrm{~F}$-deoxyglucose [3]. Abnormal fat- 
ty acid metabolism can be assessed by ${ }^{123}$ I-BMIPP $(\beta$ methyl-branched fatty acid) nuclear studies [38]. Cardiac magnetic resonance imaging can also be used to assess LV systolic function. These tests however are not specific for doxorubicin cardiomyopathy.

Antimyosin antibody study with the use of ${ }^{111} \mathrm{In}$-labeled monoclonal antimyosin antibody is used for the diagnosis of myocarditis and has also been employed for the diagnosis of doxorubicin cardiomyopathy [39]. In doxorubicin-treated patients, the sensitivity of antimyosin antibody studies is very high [40]. Various nuclear studies to detect apoptosis have been tested in animal models [41]. Annexin V, which has high affinity for membrane-bound phosphatidylserine, has been used to detect apoptosis induced by doxorubicin.

The measurements of neurohormones and cardiac enzymes have been used for the diagnosis of doxorubicin cardiotoxicity and presence of heart failure. Plasma levels of B-type natriuretic peptide are elevated and correlate with the severity of congestive heart failure [42]. The troponin T or I levels may also be increased, indicating myocardial injury [43]. The changes in neurohormones and cardiac enzymes are not diagnostic of doxorubicin cardiomyopathy and are observed in other types of cardiomyopathy. The endomyocardial biopsy may reveal characteristic diagnostic features of doxorubicin cardiomyopathy. The findings that have been suggested for the diagnosis of doxorubicin cardiomyopathy are loss of myofibrils, distention of sarcoplasmic reticulum, and vacuolization of the cytoplasm. The endomyocardial biopsy is also used to grade the severity of doxorubicin cardiotoxicity $[3,9,21]$. The disadvantage of this technique is that it is invasive, and it requires considerable experience and training. Furthermore, endomyocardial biopsies are not universally used for the diagnosis of doxorubicin cardiomyopathy and its severity.

\section{Management}

There is no specific treatment available for the management of patients with established heart failure. Diuretics are used to relieve symptoms and signs of pulmonary and systemic venous congestion. $\beta$-Adrenergic blocking agents should be considered, as for treatment of other types of systolic heart failure [44]. It has been reported that metoprolol is safe and can be effective in doxorubicin-induced cardiomyopathy [45]. However, there are no controlled studies performed to determine whether $\beta$-blocker treatments are effective to prevent progression of remodeling and to improve prognosis [44]. There is also no information available, to the best of our knowledge, whether there has been any change in prognosis of doxorubicin cardiomyopathy before and after introduction of $\beta$-blocker therapy. Angiotensin II inhibition should also be considered [3]. In patients with advanced heart failure and in those intolerant to angiotensin II inhibition therapy, low-dose hydralazine-isosorbide dinitrate combination treatment is often employed; however there is no information available to suggest that such treatment is effective in patients with doxorubicin cardiomyopathy. In patients with malignant arrhythmias, amiodarone and implantable cardioverter and defibrillator should be considered. It should be appreciated that none of the treatments employed for ischemic or idiopathic dilated cardiomyopathy has been demonstrated to improve the prognosis of patients with doxorubicin cardiomyopathy. Cardiac transplantation has been reported to improve long-term prognosis of the patients in whom the primary malignancy is cured following chemotherapy $[46,47]$. Placement of ventricular assist devices may be required before cardiac transplantation.

\section{Preventive Strategies}

To date, the major emphasis has been to limit the cumulative dose of doxorubicin to $<450 \mathrm{mg} / \mathrm{m}^{2}$ [4]. The use of anthracycline analogues, alternative methods of drug delivery and continuous slow infusion instead of standard infusion protocols have also been employed to reduce the risk of dilated cardiomyopathy. However, strategies to prevent or reduce doxorubicin cardiotoxicity have not been established [3].

A number of pharmaceutical agents have been tested, usually in experimental animal studies, to assess their potential to reduce the risk of doxorubicin cardiotoxicity (table 1). Most of the pharmacologic agents that have been tested to reduce or prevent doxorubicin cardiotoxicity have the potential to reduce oxidative stress [48]. The mercaptopropionyl glycine (MPG), a synthetic aminothiol that exhibits antioxidant properties, has been shown to reduce doxorubicin cardiotoxicity [49]. Similarly, probucol, super oxide dismutase, and dexrarzoxane with documented antioxidant properties have been reported to decrease doxorubicin cardiotoxicity [49-51]. Because the calcium channel blocker amlodipine and the $\beta$-and $\alpha$ adrenergic blocking agent carvedilol have antioxidant properties they have also been studied for their potential to reduce doxorubicin cardiotoxicity $[52,53]$. The PDE5 

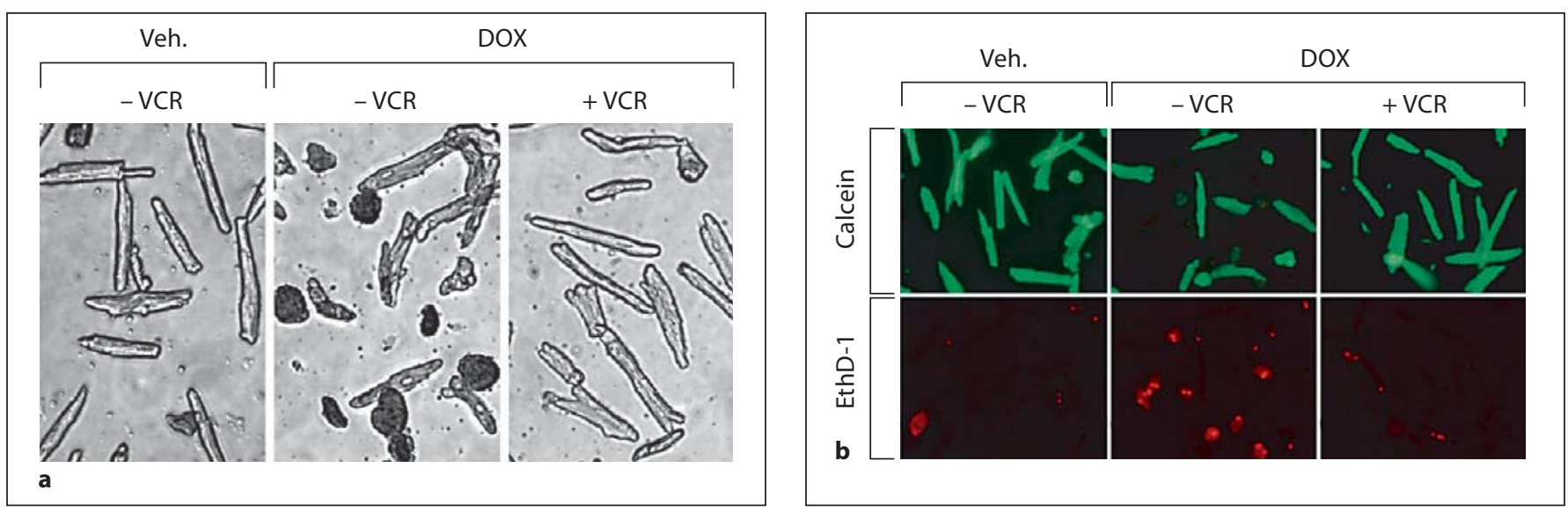

Fig. 3. a Results of trypan blue exclusion assay in a typical experiment demonstrating that co-treatment with vincristine (VCR) markedly decreases doxorubicin (DOX)-induced cardiomyocyte death. b Results of a live/ dead assay. With doxorubicin treatment alone for $24 \mathrm{~h}$ there was an increased proportion of dead cells (ethidium positive, EthD/red fluorescence) and a decreased proportion of live cells (calcein ester positive/green fluorescence) compared to vehicle treatment. With co-treatment with vincristine there were more live than dead cells. (Published with permission from Chatterjee et al. [58])

Table 1. A few pharmacologic agents that have been used to reduce doxorubicin cardiotoxicity

\section{MPG}

Probucol

Dexrazoxane

Amlodipine

Carvedilol

PDE5 inhibitor (sildenafil)

Nitric oxide

Superoxide dismutase

Endothelin receptor antagonist (bosentan)

Erythropoietin, thrombopoietin

Granulocyte colony-stimulating factor

Vincristine

inhibitor sildenafil, erythropoietin and thrombopoietin, granulocyte colony-stimulating factor, and the endothelin receptor-blocking agent bosentan have been used in experimental animal models for the protection against developing doxorubicin cardiomyopathy $[54,55]$. The potential protective role of nitric oxide and superoxide dismutase has been investigated in a transgenic mouse model. Lack of nitric oxide was associated with enhanced cardiac injury, and mitochondrial injury was attenuated by an increase in manganese superoxide dismutase [56].
In our laboratory, we found that the vinca alkaloid vincristine exerts cardioprotective effects on cultured adult mouse cardiac myocytes to chemical and hypoxic oxidative stress [57]. Vincristine is often used in combination with doxorubicin to enhance the effectiveness for treatment of the malignancy. As vincristine reduced oxidative stress in the cultured adult myocytes, we evaluated the potential cardioprotective effect of vincristine against doxorubicin cardiotoxicity in the mouse adult cell culture model [58].

Myocyte survival was quantified by the trypan blue exclusion technique, which has been validated by previous studies [59, 60]. A second technique to assess cell survival (live/dead viability/cytotoxicity assay) was also employed [58]. In figure 3, the effects of doxorubicin - either alone or in combination with vincristine - on myocyte survival during trypan blue and live/dead assays in a typical experiment are illustrated. It is clear that co-treatment with vincristine reduces the magnitude of doxorubicin-induced myocyte death [58]. The magnitude of protection by vincristine of doxorubicin-induced myocyte death is illustrated in figure 4. Exposure of cultured myocytes to 15 or $20 \mu \mathrm{g} / \mathrm{ml}$ of doxorubicin for approximately $24 \mathrm{~h}$ typically reduces myocyte survival by $50 \%$. Cotreatment with 10-30 $\mu \mathrm{mol} / \mathrm{l}$ of vincristine dramatically increased cardiomyocyte survival (>85\%) [58].

The potential protective mechanisms of vincristine in reducing doxorubicin cardiomyocyte toxicity were ex- 


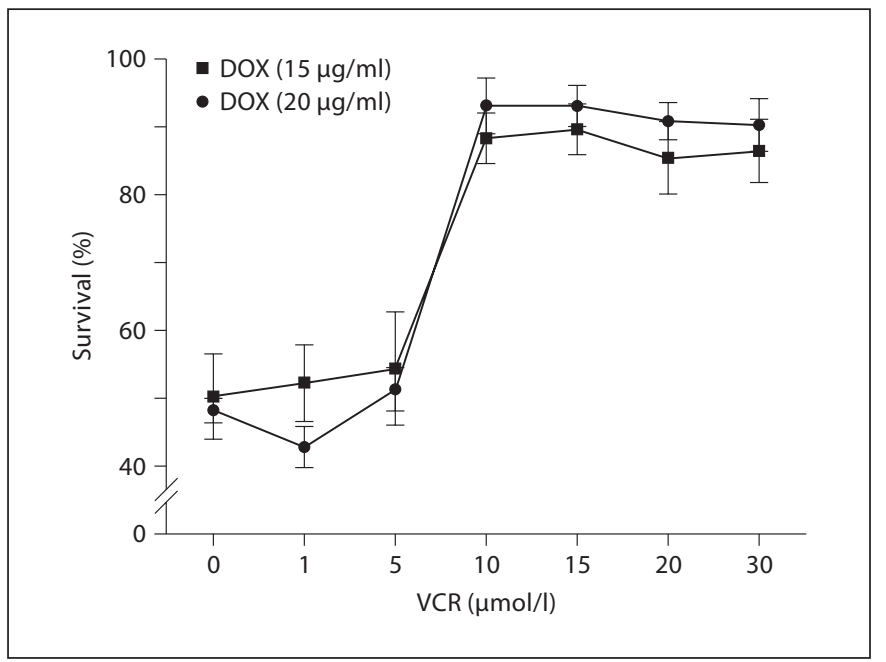

Fig. 4. The effects of increasing concentrations of vincristine (VCR) on the survival of cultured adult mouse myocytes exposed to doxorubicin (DOX; trypan blue assay). With doxorubicin treatment alone, myocyte survival was on average $50 \%$. With vincristine co-treatment, survival was $>85 \% . n=5 ;^{*} \mathrm{p}<0.05$. (Published with permission from Chatterjee et al. [58])

plored in this experimental cultured adult mouse model. Phosphorylation of the survival signals PI3-K/AKT and MEK/ERK were observed. Doxorubicin inhibits these pathways. Concomitant use of the PI3-K/AKT and MEK/ ERK inhibitors (LY294002 and PD98059, respectively) further reduced myocyte survival. During vincristine cotreatment without the inhibitors, myocyte salvage was $>85 \%$, as observed previously. With addition of the inhibitors, the magnitude of salvage by vincristine was substantially attenuated (fig. 5) [58]. These findings suggest that the protection by vincristine involves these survival pathways.

Compared to doxorubicin treatment alone, co-treatment with vincristine decreased cytochrome $c$ release, suggesting that vincristine decreases oxidative stress and inhibits mitochondrial transition. In this experimental model with cultured adult mouse myocytes, doxorubicin-induced apoptosis was assessed by TUNEL staining. Doxorubicin induces myocyte apoptosis within a few hours, which is markedly delayed with co-treatment with vincristine.

In this study, we compared the effects of vincristine to those of mercaptopropionyl glycine (which has antioxidant properties), amlodipine (a dyhydropyridine calcium channel blocker), and dexrazoxane (an iron-chelating agent). The survival of cardiomyocytes was determined

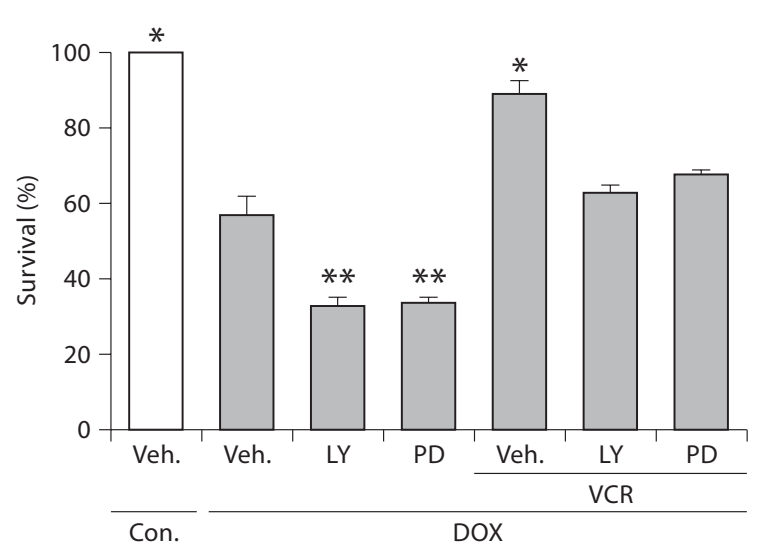

Fig. 5. The effects of pharmacologic inhibitors of PI3-K/AKT (LY294002, LY) and MEK/ERK (PD 98059, PD) on cell survival (trypan blue assay) with or without doxorubicin (DOX) and vincristine (VCR) co-treatment. Doxorubicin treatment alone was associated with decreased myocyte survival. The addition of the inhibitors further decreased survival of the cardiomyocytes. With vincristine co-treatment without the inhibitors, survival was $>85 \%$. With the addition of the inhibitors, protection by vincristine was significantly attenuated, suggesting that survival pathways are involved in the protective effect of vincristine. $\mathrm{n}=$ 5-6; ${ }^{*} \mathrm{p}<0.05$. Con. $=$ Control; Veh. $=$ vehicle. (Published with permission from Chatterjee et al. [58])

by trypan blue assay. Vincristine was superior to mercaptopropionyl glycine and amlodipine but equal to dexrazoxane in salvaging cardiomyocytes exposed to doxorubicin [58].

It should be emphasized that most of the pharmacologic agents which have the potential to reduce doxorubicin cardiotoxicity have been studied in animals, usually during acute and short-term exposure to doxorubicin. In most studies, either mice or rats have been used and short-term intraperitoneal administration of doxorubicin has been employed. Various methods to assess cardiotoxicity have been used in different studies. The effects of vincristine may differ according to the species. In our studies, we used male C57B 1/6 adult mouse strains and it remains unknown whether vincristine will exert similar protective effects or not in other mouse and animal species and humans. Also, without appropriate clinical study, whether any of these agents will be useful in the treatment of doxorubicin cardiomyopathy will remain uncertain. Although the iron-chelating agent dexrazoxane is available for clinical use, in practice it is 
used infrequently because it can induce myelosuppression.

In conclusion, doxorubicin cardiomyopathy remains a lethal disease. Extensive investigations and research have been done to understand the mechanism of doxorubicin cardiotoxicity and substantial knowledge has been accumulated. Although extensive research has also been done to find effective treatment of doxorubicin cardiomyopathy, no such treatment has been discovered. Similarly, ex- tensive research has been done and is being done to prevent doxorubicin cardiotoxicity. However, an effective preventive treatment is yet to be discovered.

\section{Acknowledgments}

We are very grateful to Lauren Poull and Arlinda LaRose for their extraordinary help in the preparation of the manuscript.

\section{References}

1 Weiss RB: The anthracyclines: will we ever find a better doxorubicin? Semin Oncol 1992;19:670-686.

2 Jordon MA: Anti-cancer agents. Cur Med Chem 2002;2:1-17.

3 Takemura G, Fujiwara H: Doxorubicin-induced cardiomyopathy from the cardiotoxic mechanisms to management. Prog Cardiovasc Dis 2007;49:330-352.

4 Swain SM, Whaley FS, Ewer MS: Congestive heart failure in patients treated with doxorubicin. A retrospective analysis of three trials. Cancer 2003;97:2869-2879.

5 Singal PK, Deally CM, Weinberg LE: Subcellular effects of Adriamycin in the heart: a concise review. J Mol Cell Cardiol 1987;19: 817-828.

6 Von Hoff DD, Layard MW, Basa P, Davis HL Jr, Von Hoff AL, Rozencweig M, Muggia FM: Risk factors for doxorubicin-induced congestive heart failure. Ann Intern Med 1979; 01:710-717.

$\checkmark 7$ Lefrak EA, Pitha J, Rosenheim S, Gottlieb JA: A clinicopathologic analysis of Adriamycin cardiotoxicity. Cancer 1973;32:302-314.

$\checkmark 8$ Broder H, Gottlieb RA, Lepor NE: Chemotherapy and cardiotoxicity. Rev Cardiovasc Med 2008;9:75-83.

\9 Billingham ME, Mason JW, Bristow MR, Daniels JR: Anthracycline cardiomyopathy monitored by morphologic changes. Cancer Treat Rep 1978;62:865-872.

-10 Buja LM, Ferrans VJ, Mayer RJ, Roberts WC, Henderson ES: Cardiac ultrastructural changes induced by daunorubicin therapy. Cancer 1973;32:771-788

11 Gewirtz DA: A critical evaluation of the mechanisms of action proposed for the antitumor effects of the anthracycline antibiotics Adriamycin and daunorubicin. Biochem Pharmacol 1999;57:727-741.

12 Minotti G, Menna P, Salvatorelli E, Cairo G, Gianni L: Anthracyclines: molecular advances and pharmacologic developments in antitumor activity and cardiotoxicity. Pharmacol Rev 2004;56:185-229.
13 Kalyanaraman B, Perez-Reyes E, Mason RP: Spin-trapping and direct electron spin resonance investigations of the redox metabolism of quinone anticancer drugs. Biochim Biophys Acta 1980;630:119-130.

14 Doroshow JH: Effect of anthracycline antibiotics on oxygen radical formation in rat heart. Cancer Res 1983;43:460-472.

15 Singal PK, Segstro RJ, Singh RP, Kutryk MJ: Changes in lysosomal morphology and enzyme activities during the development of Adriamycin-induced cardiomyopathy. Can J Cardiol 1985;1:139-147.

16 Doroshow JH, Locker GY, Baldinger J, Myers CE: The effect of doxorubicin on hepatic and cardiac glutathione. Res Commun Chem Pathol Pharmacol 1979;26:285-295.

17 Olson RD, MacDonald JS, van Boxtel CJ, Boerth RC, Harbison RD, Slonim AE, Freeman RW, Oates JA: Regulatory role of glutathione and soluble sulfhydryl groups in the toxicity of Adriamycin. J Exp Ther 1980;215: 450-454.

18 Odom AL, Hatwig CA, Stanley JS, Benson AM: Biochemical determinants of Adriamycin toxicity in mouse liver, heart and intestine. Biochem Pharmacol 1992,43:831-836.

19 Arena E, D’Alessandro N, Dusonchet L, Geraci M, Rausa L, Sanguedolce R: Repair kinetics of DNA, RNA and proteins in the tissues of mice treated with doxorubicin. Arzneimittelforschung 1979;29:901-902.

20 Monti E, Prosperi E, Supino R, Bottiroli G: Free radical-dependent DNA lesions are involved in the delayed cardiotoxicity induced by Adriamycin in the rat. Anticancer Res 1995;15:193-197.

21 Bristow MR, Sageman WS, Scott RH, Billingham ME, Bowden RE, Kernoff RS, Snidow GH, Daniels JR: Acute and chronic cardiovascular effects of doxorubicin in the dog: the cardiovascular pharmacology of drug-induced histamine release. J Cardiovasc Pharmacol 1980;2:487-515.

22 Tong J, Ganguly PK, Singal PK: Myocardial adrenergic changes at two stages of heart failure due to Adriamycin treatment in rats. Am J Physiol Heart Circ Physiol 1991;260: H909-H916.
23 Davies KJ, Doroshow JH: Redox cycling of anthracyclines by cardiac mitochondria. 1 . Anthracycline radical formation by $\mathrm{NADH}$ dehydrogenase. J Biol Chem 1986;261:30603067.

24 Berlin V, Haseltine WA: Reduction of Adriamycin to a semiquinone-free radical by NADPH cytochrome P-450 reductase produces DNA cleavage in a reaction mediated by molecular oxygen. J Biol Chem 1981;256: 4747-4756.

25 Bachur NR, Gordon SL, Gee MV: NADPH cytochrome P-450 reductase activation of quinine anticancer agents to free radicals. Proc Natl Acad Sci USA 1979;76:954-957.

26 Vasquez-Vivar J, Martasek P, Hogg N, Masters BS, Pritchard KA Jr, Kalyanaraman B: Endothelial nitric oxide synthase-dependent superoxide generation from Adriamycin. Biochemistry 1997;36:11293-11297.

27 Kalivendi SV, Kotamraju S, Zhao H, Joseph J, Kalyanaraman B: Doxorubicin-induced apoptosis is associated with increased transcription of endothelial nitric-oxide synthase. Effect of antiapoptotic antioxidants and calcium. J Biol Chem 2001;276:4726647276.

28 Kotamraju S, Konorev EA, Joseph J, Kalyanaraman B: Doxorubicin-induced apoptosis in endothelial cells and cardiomyocytes is ameliorated by nitrone spin traps and ebselen. Role of reactive oxygen and nitrogen species. J Biol Chem 2000;275:33585-33592.

29 Kim Y, Ma A, Kitta K, Fitch SN, Ikeda T, Ihara Y, Simon AR, Evans T, Suzuki YJ: Anthracycline-induced suppression of GATA-4 transcription factor: implication in the regulation of cardiac myocyte apoptosis. Mol Pharmacol 2003;63:368-377.

30 Aries P, Paradis P, Lefevre C, Schwartz RJ, Nemer M: Essential role of GATA-4 in cell survival and drug-induced cardiotoxicity. Proc Natl Acad Sci USA 2004;101:69756980.

- 31 Lou H, Danelisen I, Singal PK: Involvement of mitogen-activated protein kinases in Adriamycin-induced cardiomyopathy. Am J Physiol Heart Circ Physiol 2005;288:H1925H1930. 
-32 Wang L, Ma W, Markovich R, Chen JW, Wang PH: Regulation of cardiomyocyte apoptotic signaling by insulin-like growth factor I. Circ Res 1998;83:516-522.

-33 Arola QJ, Saraste A, Pulkki K, Kallajoki M, Parvinen M, Voipio-Pulkki LM: Acute doxorubicin cardiotoxicity involves cardiomyocyte apoptosis. Cancer Res 2000;60:17891792.

-34 Sawyer DB, Fukazawa R, Arstall MA, Kelly RA: Daunorubicin-induced apoptosis in rat cardiac myocytes is inhibited by dexrazoxane. Circ Res 1999;84:257-265.

-35 Wang S, Leonard SS, Ye J, Ding M, Shi X: The role of hydroxyl radical as a messenger in $\mathrm{Cr}(\mathrm{VI})$-induced p53 activation. Am J Physiol Cell Physiol 2000;279:C868-C875.

>36 Huang C, Zhang Z, Ding M, Li J, Ye J, Leonard SS, Shen HM, Butterworth L, Lu Y, Costa M, Rojanasakul Y, Castranova V, Vallyathan V, Shi X: Vanadate induces p53 transactivation through hydrogen peroxide and causes apoptosis. J Biol Chem 2000;275: 32516-32522.

>37 Sisson JC, Wieland DM, Sherman P, Mangner TJ, Tobes MC, Jacques S Jr: Meta-iodobenzylguanidine as an index of the adrenergic nervous system integrity and function. J Nucl Med 1987;28:1620-1624.

38 Wakasugi S, Fischman AJ, Babich JW, Callahan RJ, Elmaleh DR, Wilkinson R, Strauss HW: Myocardial substrate utilization and left ventricular function in Adriamycin cardiomyopathy. J Nucl Med 1993;34:12831529.

-39 Hiroe M, Ohta Y, Fujita N, Nagata M, Toyozaki T, Kusakabe K, Sekiguchi M, Marumo F: Myocardial uptake of ${ }^{111}$ In in monoclonal antimyosin Fab in detecting doxorubicin cardiotoxicity in rats. Morphological and hemodynamic findings. Circulation 1992; 86:1965-1972.

-40 Estorch M, Carrio I, Berna L, MartinezDuncker C, Alonso C, Germa JR, Ojeda B: Indium-111-antimyosin scintigraphy after doxorubicin therapy in patients with advanced breast cancer. J Nucl Med 1990;31: 1965-1969.

-41 Koopman G, Reutelingsperger CP, Kuijten GA, Keehnen RM, Pals ST, van Oers MH: Annexin $\mathrm{V}$ for flow cytometric detection of phosphatidylserine expression on B cells undergoing apoptosis. Blood 1994;84:14151420 .
42 Suzuki T, Hayashi D, Yamazaki T, Mizuno T, Kanda Y, Komuro I, Kurabayashi M, Yamaoki K, Mitani K, Hirai H, Nagai R, Yazaki Y: Elevated B-type natriuretic peptide levels after anthracycline administration. Am Heart J 1998;136:362-363.

43 Morandi P, Ruffini PA, Benvenuto GM, Raimondi R, Fosser V: Serum cardiac troponin I levels and ECG/echo monitoring in breast cancer patients undergoing high-dose (7 $\mathrm{g} / \mathrm{m}^{2}$ ) cyclophosphamide. Bone Marrow Transplant 2001;28:277-282.

44 Malcom J, Arnold O, Howlett JG, Ducharme A, Ezekowitz JA, Gardner MJ, Giannetti N, Haddad H, Heckman GA, Isaac D, Jong P, Liu P, Mann E, McKelvie RS, Moe GW, Svendsen AM, Tsuyuki RT, O’Halloran K, Ross HJ, Sequeira EJ, White M, Canadian Cardiovascular Society: Canadian Cardiovascular Society Consensus Conference Guidelines on Heart Failure - 2008 Update: best practices for the transition of care of heart failure patients, and the recognition, investigation and treatment of cardiomyopathies. Can J Cardiol 2008;24:21-40.

45 Shaddy RE, Olsen SL, Bristow MR, Taylor DO, Bullock EA, Tani LY, Renlund DG: Efficacy and safety of metoprolol in the treatment of doxorubicin-induced cardiomyopathy in pediatric patients. Am Heart J 1995; 129:197-199.

46 Arico M, Pedroni E, Nespoli L, Vigano M, Porta F, Burgio GR: Long-term survival after heart transplantation for doxorubicin-induced cardiomyopathy. Arch Dis Child 1991; 66:985-986

47 Thomas X, Le QH, Fiere D: Anthracyclinerelated toxicity requiring cardiac transplantation in long-term disease-free survivors with acute promyelocytic leukemia. Ann Hematol 2002;81:504-507.

48 Singal PK, Illiskovic N: Doxorubicin-induced cardiomyopathy. N Engl J Med 1998; 339:900-905.

49 El-Missiry MA, Othman AI, Amer MA, Abd El-Aziz MA: Attenuation of the acute Adriamycin-induced cardiac and hepatic oxidative toxicity by $\mathrm{N}$-(2-mercaptopropionyl) glycine in rats. Free Radic Res 2001;35:575581.

50 Lipshultz SE, Rifai N, Dalton VM, Levy DE, Silverman LB, Lipsitz SR, Colan WSD, Asselin BL, Clavell LA, Hurwitz CA, Moghrabi RD, Samson Y, Schorin MA, Gelber RD, Sallan SE: The effect of dexrazoxane on myocardial injury in doxorubicin-treated children with acute lymphoblastic leukemia. N Engl J Med 2004;351:145-153.
51 Singal PK, Siveski-Iliskovic N, Hill M, Thomas PT, Li T: Combination therapy with probucol prevents Adriamycin-induced cardiomyopathy. J Mol Cell Cardiol 1995;27: 1055-1063.

-52 Yamanaka S, Tatsumi T, Shiraishi J, Mano A, Keira N, Matoba S, Asayama J, Fushiki S, Fliss H, Nakagawa M: Amlodipine inhibits doxorubicin-induced apoptosis in neonatal rat cardiac myocytes. J Am Coll Cardiol 2003,41:870-878

-53 Kalay N, Basar E, Ozdogru I, Er O, Cetinkaya Y, Dogan A, Inanc T, Oguzhan A, Eryol NK, Topsakal R, Ergin A: Protective effects of carvedilol against anthracycline-induced cardiomyopathy. J Am Coll Cardiol 2006;48: 2258-2262.

54 Fisher PW, Salloum F, Das A, Hyder H, Kukreja RC: Phosphodiesterase-5 inhibition with sildenafil attenuates cardiomyocyte apoptosis and left ventricular dysfunction in a chronic model of doxorubicin cardiotoxicity. Circulation 2005;111:1601-1610.

55 Bien S, Riad A, Ritter CA, Gratz M, Olshausen F, Westermann D, Grube M, Kreig T, Ciecholewski S, Felix SB, Staudt A, Schultheiss H, Ewart R, Volker U, Tschope C, Kroemer HK: The endothelin receptor blocker bosentan inhibits doxorubicin-induced cardiomyopathy. Cancer Res 2007;67:1042810435.

56 Cole MP, Chaiswing L, Oberley TD, Edelmann SE, Piascik MT, Lin S, Kiningham KK, St Clair DK: The protective roles of nitric oxide and superoxide dismutase in Adriamycin-induced cardiotoxicity. Cardiovasc Res 2006;69:186-197.

57 Chatterjee K, Zhang J, Honbo N, Simmonis U, Shaw R, Karliner JS: Acute vincristine pretreatment protects adult mouse cardiac myocytes from oxidative stress. J Mol Cell Cardiol 2007;43:327-336.

58 Chatterjee K, Zhang J, Tao R, Honbo N, Karliner JS: Vincristine attenuates doxorubicin cardiotoxicity. Biochem Biophysical Res Commun 2008;373:555-560.

59 Karliner JS, Honbo N, Summers K, Gray MO, Goetzl EJ: The lysophospholipids sphingosine-1-phosphate and lysophosphatidic acid enhance survival during hypoxia in neonatal rat cardiac myocytes. J Mol Cell Cardiol 2001;33:1713-1717.

60 Gray MO, Karliner JS, Mochly-Rosen D: A selective epsilon-protein kinase $\mathrm{C}$ antagonist inhibits protection of cardiac myocytes from hypoxia-induced cell death. J Biol Chem 1997;272:30945-30951. 